\section{Bridging the gap between chronic cerebrospinal venous insufficiency and Ménière disease}

\author{
Dario C. Alpini, ${ }^{1}$ Pietro M. Bavera, ${ }^{2}$ \\ Federica Di Berardino, ${ }^{3}$ Stefania Barozzi, ${ }^{1}$ \\ Piero Cecconi, ${ }^{4}$ Mario Farabola, ${ }^{4}$ \\ Valentina Mattei, ${ }^{1}$ Laura Mendozzi, ${ }^{5}$ \\ Luigi Pugnetti, ${ }^{6}$ Antonio Cesarani ${ }^{4}$ \\ 'Ear Nose Throat-Otoneurology Service, \\ IRCCS S. Maria Nascente don Carlo \\ Gnocchi Foundation, Milano; ${ }^{2}$ Vascular \\ Imaging Diagnostician for Medick-Up \\ Vascular Lab, Milano; ${ }^{3}$ Department of \\ Clinical and Community Sciences, \\ University of Milan and Audiology Unit, \\ IRCCS Foundation, Ca' Granda Ospedale \\ Maggiore Policlinico, Milano; \\ ${ }^{4}$ Neuro-Radiology, IRCCS S. Maria \\ Nascente don Carlo Gnocchi Foundation, \\ Milano; ${ }^{5}$ Department of Neurology- \\ Multiple Sclerosis, IRCCS S. Maria \\ Nascente don Carlo Gnocchi Foundation, \\ Milano; ${ }^{\circ}$ Neurophysiology Service, IRCCS \\ S. Maria Nascente don Carlo Gnocchi \\ Foundation, Milano, Italy
}

\section{Abstract}

Ménière disease (MD) is a chronic illness of the inner ear that affects a substantial number of patients every year worldwide. Because of a dearth of well-controlled studies, the medical and surgical management of MD remains quite empirical. The main reason is that it is very difficult to investigate patients affected with Certain MD due to the post-mortem criterion necessary for this diagnostic grade. Although endolymphatic hydrops (EH) is the worldwideaccepted mechanism of MD, the causes that induce it are still not clear. In fact MD has been correlated mostly to a wide and different disturbances ranging from trauma to sleep disorders. It is nowadays sufficiently demonstrated that chronic cerebrospinal venous insufficiency (CCSVI) is very frequent in MD. Even if CCSVI may potentially induce $\mathrm{EH}$ through a pure hydraulic mechanism CCSVI, per se does not explain how the various disorders correlated with MD may interact with CCSVI and provoke EH. The aim of this review is an attempt to approach MD into the context of the more recent findings about the global brain waste clearance system, to which inner ear is anatomically and functionally connected, in order to build a reasonable model of MD pathogenesis. The major part of the diseases correlated to MD may act on the inner ear disturbing the glym- phatic (GS) and/or brain lymphatic system (BLS) activity. The venous system interplays with GS and BLS. In this model CCSVI is considered more than a direct cause of MD rather the anatomical predisposition to develop the disease. In this model $\mathrm{EH}$, and then $\mathrm{MD}$, is the consequence of a failure of the compensation of the congenital venous abnormalities, anatomical compensation as collateral pathways and/or functional compensation as GS and BLS. In this model the major part of the disturbances correlated to MD and the various treatment proposed find their appropriate placement.

\section{Introduction}

Ménière's disease (MD) is a chronic illness of the inner ear that affects a substantial number of patients every year worldwide. In Europe the incidence is about $50-200 / 100,000$ a year. ${ }^{1}$ The disease is characterized by intermittent episodes of vertigo lasting from minutes to hours, with sensorineural, usually fluctuating, hearing loss, tinnitus, and aural pressure. Attacks of vertigo may come on suddenly or after a short period of tinnitus or muffled hearing. Inner ear diseases, including MD, are usually considered as peripheral diseases but, especially for the reasons that this paper concern, it is necessary to highlight at least three aspects that oblige the clinicians, at least under the therapeutic point of view, to approach the inner ear as a central organ: inner ear structures are deeply embedded into the petrous part of the temporal bone, the unique ivory bony part of the skull: i) inner ear vascularization is provided by a long slender branch of the anterior inferior cerebellar artery ( $>85 \%$ cases) or basilar artery ( $<15 \%$ cases) through the labyrinthine artery (also named auditory artery or internal auditory artery), that accompanies the vestibulo-cochlear nerve through the internal acoustic meatus; ii) inner ear drainage is formed by the labyrinthine veins that accompany the branches of auditory artery from the vestibule and semicircular canals via the inferior petrous sinus into the internal jugular veins (IJVs). MD may be classified according to the worldwide still accepted guide-lines published in 1995 by the Committee on Hearing and Equilibrium of the American Academy of Otology - Head and Neck Surgery, into different grades of certainty (Table 1). ${ }^{2}$

Because of a dearth of well-controlled studies, the medical and surgical management of MD remains quite empirical. The main reason is that it is very difficult to investigate patients affected with certain $M D$ due to the postmortem criterion necessary for this diagnostic grade. Therefore every research is substantially conducted on patients with a lower diagnostic grade due to the impossibility to conduct
Correspondence: Dario Carlo Alpini, Ear Nose Throat-Otoneurology Service, IRCCS S. Maria Nascente don Carlo Gnocchi Foundation, Vertigo School, via Lomellina 58, 20133 Milano, Italy.

E-mail: dario.alpini@fastwebnet.it

Key words: Ménière disease; chronic cerebrospinal venous insufficiency; glymphatic system; brain lymphatic system; hearing loss; multiple sclerosis; jugular veins; vertigo.

Conflict of interest: the authors declare no potential conflict of interest.

Contributions: DCA and PMB conceived and designed the paper; SB and VM selected the appropriate Definite MD patients; FDB analyzed the data regarding MD patients; DCA and AC drafted the article; $\mathrm{PC}$ and MF analyzed the data regarding MRI in MD patients; LM and LP critically revised the paper for important intellectual content.

Paper partially presented at $35^{\text {th }}$ Congress of Società Italiana Audiologia e Foniatria (SIAF, Italian Society of Audiology and Phoniatry), Milano, Italy, December $16^{\text {th }} 2015$.

Poster presented at $6^{\text {th }}$ Annual ISNVD Meeting, New York City, USA, April $29^{\text {th }} 2016$.

Received for publication: 15 December 2015. Revision received: 10 May 2016.

Accepted for publication: 11 May 2016.

This work is licensed under a Creative Commons Attribution 4.0 License (by-nc 4.0).

(C) Copyright D.C. Alpini et al., 2016

Licensee PAGEPress, Italy

Veins and Lymphatics 2016; 5:5687

doi:10.4081/vl.2016.5687

control studies on certain $M D$. Every research on MD is thus conditioned by this bias. For this reason, in our opinion, every research substantially has to be considered as a high level speculation with a reasonable certainty grade.

The aim of this paper is an attempt to approach MD into the context of the more recent findings about the global brain waste clearance system to which inner ear is anatomically and functionally connected in order to build a reasonable model of MD pathogenesis.

\section{Ménière disease and chronic cerebrospinal venous insufficiency}

MD is substantially characterized by three symptoms, vertigo, hearing loss and tinnitus, it is generally correlated to a lot of causes and it is sustained by only one worldwide accepted 
hydraulic pathogenetic mechanism: the endolymphatic hydrops (EH). Paparella ${ }^{3}$ used the notion of lake-river-pond to explain the occurrence of malabsorption of endolymph leading to hydrops. This notion describes the endolymphatic sac (ES) as a pond, with the vestibular aqueduct (the river) connecting it to the endolymphatic fluid space that is like a lake. When there is an obstruction near the ES or duct, a backlog of endolymphatic fluid is created, leading to hydrops. The causes of this kind of malabsorption of endolymph leading to hydrops are still debated.

At the beginning of our personal experiences on chronic cerebrospinal venous insufficiency (CCSVI) we observed, quite incidentally, a possible correlation between CCSVI and inner ear disorders. ${ }^{4}$ In fact, comparing echocolor Doppler (ECD) findings in multiple sclerosis (MS) and in a controlled group of patients affected with different disorders we found only three controls out of sixty showing venous flow abnormalities: all of them had been affected by sudden hearing loss. Thus, we begun to extensively investigate CCSVI in a large sample of subjects affected with audiovestibular disorders, including MD.

In 2013 Alpini and colleagues described a patient affected with ${ }^{5}$ bilateral CCSVI and bilateral sudden sensorineural hearing loss (SSHL). In 2013 Alpini and colleagues ${ }^{6}$ compared ECD arterial and venous tests in patients affected with cochleo-vestibular disturbances subdivided into three groups: definite unilateral MD, non-MD cochleo-vestibular impairment and patients affected with benign paroxysmal positioning vertigo with cochlear hearing loss. This paper showed that asymmetrical venous flow was more frequent in MD patients than in others. Successively Di Berardino and colleagues ${ }^{7}$ investigated CCSVI in MD using both ECD and magnetic resonance imaging (MRI) confirming the high cor- relation between CCSVI and MD. This correlation is further supported by Filipo and colleagues. ${ }^{8}$ Bruno and colleagues ${ }^{9}$ performed percutaneous transluminal angioplasty (PTA) in $20 \mathrm{MD}$ CCSVI-positive patients obtaining at six-months follow-up significant improvement of symptoms (hearing loss and acute vertigo spells) in 19. In 2015 Bavera and colleagues presented at the $5^{\text {th }}$ ISNVD Annual Meeting in Naples a comparison of CCSVI characteristics into three groups of patients: MD, MS and other non-MD cochleo-vestibular disturbances. Incidence of CCSVI in MD and MS was, as expected, high, according to previous literature findings..$^{10}$ Comparing CCSVI findings in MS $v$ MD, the Authors showed that the level of venous abnormalities was different: J1 in MS and J3 in MD (Figure 1).

Venous alterations are differently distributed according to the kind of disease. Distribution is expressed in \% of abnormal examinations. J3I is the most involved level in MD (27 definite Ménière patients); J1 is the most involved level in MS (70 clinically definite patients); in the group other vestibular disorders (51 patients) venous alterations are rare but $\mathrm{J} 3$ is still the most represented level. This figure has been redrawn from that presented by Bavera and colleagues at the $5^{\text {th }}$ ISNVD Meeting.

Also Filipo and colleagues ${ }^{8}$ observed that MD patients showed the prevalence of proximal venous abnormalities with $76 \%$ of unidirectional venous return in the petrosal sinuses. Petrosal sinuses are directly involved in the drainage of the inner ear.

In 2016 Vannini and colleagues at the $6^{\text {th }}$ ISNVD Meeting ${ }^{11}$ presented a comparison between SSHL and MD patients regarding presence and characteristics of IJVs valves showing substantial differences in the two groups confirming, in this way, a certain disease-specificity of CCSVI.

Hence, it seems nowadays reasonable to state that CCSVI may be the anatomical background to develop EH in MD, at least in definite and probable MD patients.

\section{Model of brain circulation in chronic cerebrospinal venous insufficiency and its correlation with Ménière disease}

The mechanism leading from CCSVI to MD is still debated. Both Di Berardino and colleagues ${ }^{7}$ and Filipo and colleagues ${ }^{8}$ proposed a hydraulic disorder, or venous vasculitis or the microangiopathic changes usually associated with chronic venous insufficiency.

The blood-labyrinth barrier is impaired in association with the EH. ${ }^{12}$ The luminal compartment of the inner ear, the endolymphatic space, is separated by the abluminal compartment, the perilymphatic space, by highly specialized epithelial cells with tight junctions. The endolymphatic space contains luminal fluid with high potassium $\left(\mathrm{K}^{+}\right)$concentration and low sodium $\left(\mathrm{Na}^{+}\right)$concentration, which provides the ionic milieu needed to sustain transduction of sound and head acceleration into VIII cranial nerve impulses. The fluid volume within the bony labyrinth remains constant. Changes in the volumes of the endolymphatic and perilymphatic compartments are responses to osmotic gradients between the compartments themselves. ${ }^{13}$ Perilymph is connected fairly directly to spinal fluid pathways via the cochlear canaliculus. When spinal fluid pressure changes, perilymph pressure changes within about $10 \mathrm{~s}$. The composition of endolymph is maintained by stria vascularis, that is the seat of $\mathrm{K}^{+}$secretion. Stria vascularis

Table 1. The worldwide accepted and used diagnostic Ménière disease guidelines. It is interesting to highlight that the grade of certainty is established to be possible only with post mortem confirmation.

\section{The American Academy of Otolaryngology - Head and Neck Surgery Criteria for diagnosis of Ménière's disease}

The definition of the disease requires the combination of

1. Recurrent spontaneous and episodic vertigo. A definitive spell of vertigo lasting at least 20 min, often prostrating, accompanied by disequilibrium that can last several days; usually nausea or vomiting, or both; no loss of consciousness. Horizontal rotatory nystagmus is always present

2. Hearing loss (not necessarily fluctuating)

3. Either aural fullness or tinnitus, or both

The classification of the disease is graded as follows

Certain Ménière's disease_ Definite disease plus post mortem confirmation

Definite Ménière's disease $\quad$ Two or more definitive episodes of vertigo plus audiometrically confirmed sensorineural hearing loss, plus tinnitus, aural fullness, or both

Probable Ménière's disease One definitive episode of vertigo plus audiometrically confirmed sensorineural hearing loss plus tinnitus, aural fullness, or both; other causes excluded

Possible Ménière's disease

Episodes of vertigo with no associated hearing loss or hearing loss with non-definitive disequilibrium; other causes excluded 
is densely vascularized compared with the avascular Reissner's membrane and singlevessel metabolic supply of the Outer Sulcus. Reissner's membrane is thought to be primarily responsible for $\mathrm{Na}^{+}$homeostasis of cochlear endolymph. Outer Sulcus epithelium is located in the lateral cochlear wall, it is capable of absorbing $\mathrm{Na}^{+}$and provides a parasensory shunt for $\mathrm{K}^{+}$efflux. ${ }^{14}$ Endolymph is coupled more indirectly to cerebrospinal fluid (CSF) pressure and air pressure, through membranes. One pathway is via the endolymphatic duct, to the sac, and the dural membrane. Another is via the membranes that separate the endolymphatic and perilymphatic compartments. Normally, there is little flow of endolymph either radially or longitudinally. If endolymphatic volume becomes excessive it is reabsorbed back into the stria vascularis by means of radial flow. When there is a largest volume increase endolymph move longitudinally into the ES. The ES is a blind pouch, its epithelial cells consist primarily of two types: mitochondria-rich cells and ribosome-rich cells but little is known about the ion transport properties of each cell type. ES is placed on the posterior surface of the petrous portion of the temporal bone, where it is in contact with the dura mater and perform both absorptive and secretory, as well as phagocytic and immunodefensive, functions.

In this way the underlying mechanism of $\mathrm{EH}$ is still debated, with some researches in favor of a purely hydraulic mechanism and others hypothesizing a control mechanism of ionic balance. Hydraulic hypothesis supports ES surgery, while control hypothesis pharmacologic treatments.

On the other hand, several studies analyzing the temporal bone anatomy in MD patients have found consistent alterations in the arrangement of the sigmoid sinus, anteriorly or medially displaced, and jugular bulb abnormalities (JBA)..$^{15}$ For these reason sac-vein decompression ${ }^{16}$ seems to be more effective that sac decompression alone.

If the role of intracranial veins in causing abnormalities of inner ear metabolism and then labyrinth function is easy to understand, more difficult is to correlate alterations of neck vein structures on cerebral venous hemodynamics.

Müller and Toro ${ }^{17}$ described a mathematical model for the cardiovascular system in order to describe the complex interaction between intracranial pressure and cerebral vasculature and the Starling-resistor like behavior of the intracranial veins.

The cranial cavity is a space of fixed volume containing parenchyma, the brain, and fluids, CSF and blood, fluids functionally connected: variations in intracranial blood volume produce fluctuations of intracranial pressure and, consequently, exchange of CSF between the intracranial and spinal subarachnoid spaces. In this way ${ }^{18}$ blood volume may regulate glimphatic system. ${ }^{19}$ Furthermore, variations in intracranial blood volume ${ }^{20}$ may potentially influence on brain lymphatic system..$^{21}$

Intracranial veins are flexible tubes that drain into the various dural sinuses, located in the dura madre and therefore more rigid than cerebral veins.

Starling resistor is a an experimental device in which a collapsible tube, like an intracranial vein or IJV, is connected to two rigid tubes, like the dural sinuses, at its extremities and located in a chamber of fixed volume with variable ambient pressure, like the cranial cavity.

The pressure difference that regulate cerebral blood flow (CBF) both to feed brain parechima and to drain waste products of the brain parenchima metabolism, is depending on the difference between arterial and intracranial pressure, so called cerebral perfusion pressure. $\mathrm{CBF}$ is considered as a flow phenomenon governed by a Sterling resistor. ${ }^{18}$

CSF filtration from the subarchnoid space towards the dural sinuses varies linearly with the difference between intracranial pressure and superior sagittal sinus pressure.

The model proposed by the Authors indicates that the leading mechanism of Starlingresistor like behavior of intracranial veins is at the point where they join dural sinuses.

Structural, like JBA, or functional, like in CCSVI, abnormalities of the cervico-cephalic veins may impair drainage of the inferior petrosal sinuses through increased pressure or blood reflux into the sinuses. ${ }^{8}$ In this way, labyrinth drainage into the petrosal sinuses through endolymphatic radial flow, by means of the cochlear and the vestibular aqueduct veins, and longitudinal flow, by means of ES, is impaired. These phenomena increase inner ear pressure, leading to $\mathrm{EH}$, and/or induce alteration in $\mathrm{K}^{+} / \mathrm{Na}^{+}$balance in the inner ear fluids, provoking MD attacks.

Furthermore, since many of the venous vessels in the scala tympani have little or no bony covering and are essentially exposed to the perilymphatic space, ${ }^{22}$ the venous system cold become a route of entry for the cells participating in the inner ear inflammatory process especially if slowing or refluxing of venous flow as observed in CCSVI, prolong the persistence of toxins, autoantibodies or pathogens into the inner ear like viruses ${ }^{23-25}$ free radicals ${ }^{26}$ and cochlear autoantibodies, like HSP 70.27

MD has been correlated also to migraine ${ }^{28,29}$ but CCSVI has been described also in chronic migraine patients..$^{30}$ Since, generally speaking, venous flow may be depending also on global circulating blood volume, it is possible that hyperidric diet ${ }^{31}$ frequently proposed to MD patients, may act directly facilitating braininner ear venous drainage.

Some aspects of MD may be explained also without considering CCSVI. For example, lifestyle changes and hypertension ${ }^{32}$ treatment, including salt restriction, ${ }^{33}$ one of the most popular treatment regimen in MD and continuous positive airway pressure in obstructive

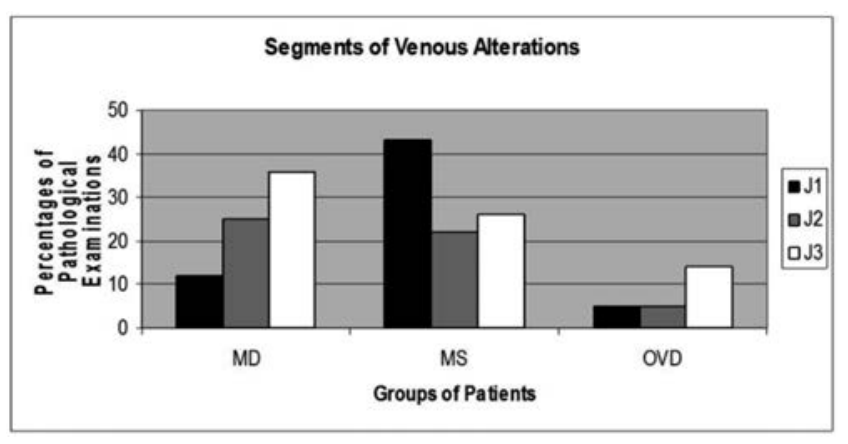

Figure 1. Distribution of levels of detected venous abnormalities in three groups of patients. MD, Ménière disease; MS, multiple sclerosis; OVD, other vestibular disorders.

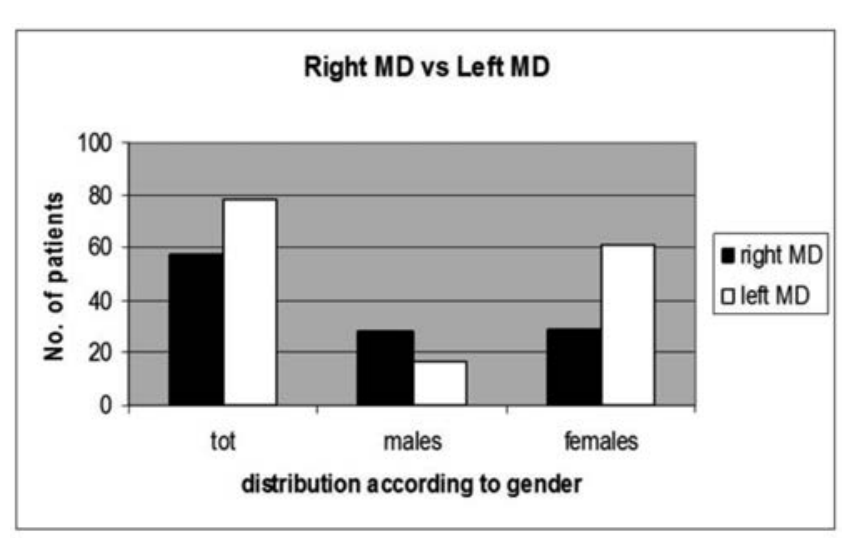

Figure 2. Distribution of side of Ménière disease (MD) in relation with gender. 
sleep apnea syndrome (OSAS), ${ }^{34}$ may act directly on inner ear vascularization ${ }^{35}$ and therefore on endolymph production, frank hypoglycemia ${ }^{36}$ and hyperinsulinemia, rather than diabetes, ${ }^{37-39}$ it is known to alter $\mathrm{Na}^{+} / \mathrm{K}^{+}$ inner ear pump, the same pump on which is supposed acts proton pump inhibitors. ${ }^{40}$

Since MD has been correlated mostly to a wide and different diseases and treatments in addition to those mentioned above, ${ }^{41}$ CCSVI may be considered more than a cause of MD per se, rather the anatomical predisposition to develop the disease.

The role of IJVs in MD has been extensively investigated and IJVs abnormalities are substantially considered the main alteration that may condition the onset of the disease. On the other hand, IJV it is known to be main route of venous drainage when supine. The extracranial venous circulation is strongly influenced by posture as demonstrated by Gadda and colleagues $^{42}$ that correlated, in a simulated model, the cross-sectional area and the perimeter of joint vibration analysis during the cardiac cycle. Authors showed that IJV is completely distended in supine position and collapsed when standing. In both postures vertebral veins drain the brain, in general, and, particularly, the brainstem and the cerebellum.

A retrospective review of MRI performed in the MD patients that we studied for the previous paper on CCSVI in MD, ${ }^{6,7,10}$ showed compensatory hypertrophy of vertebral plexus or vertebral veins or both in all the patients that presented IJVs abnormalities.

The complex connection between the inner ear and the neck ${ }^{43}$ support the idea that a disturbed labyrinth leads to a disturbance of headto-neck position control and neck function increasing drainage difficulties through deep cervical muscles compression of the vertebral plexus. Furthermore, the idea that IJVs do not compensate primarily impaired vertebral drainage dysfunction had to be taken in account.

Mülle and Toro observed ${ }^{17}$ flow distribution asymmetry between right and left transverse sinuses and, consequently, between left and right IJV. It is interesting to note that Simka and colleagues ${ }^{44}$ showed that in MS venous malformations were more commonly found on the left side. The prevalence of left internal jugular vein malformations was $81.7 \%$ vs $64.0 \%$ on the right side. Similarly, blockages were found only in the left and not in the right brachiocephalic vein. Same findings in MS have been recently reported by Bavera. ${ }^{45}$ Herman, ${ }^{46}$ in 1993 reported predominance of left ear in MD, sudden deafness, and inner ear damage. Successively, in 2014 Reiss and Reiss $^{47}$ confirmed the prevalence of left SSHL at least in females.

We conducted a retrospective evaluation of 135 patients (mean age $43 \pm 6$ years) affected with definite unilateral MD. MD affected the right side in 57 and the left side in 78 with the slight left expected prevalence (57\%). But, right MD regarded 29 females (51\%) while left MD regarded only 17 males with a prevalence of $78 \%$ of females (Figure 2). In our experience the correlation between the MD side and prevalent venous abnormalities side is $87 \%$. Therefore, our experience confirms the left prevalence either of CCSVI or MD. CCSVI is considered to be a congenital venous malformation. In adults, the IJVs that drain the brain develops from precardinal veins in the embryo. ${ }^{48}$ These precardinal veins mostly join the common cardinal veins, in the area where, in an adult, the jugular valve is found. As stated by Simka and colleagues ${ }^{44}$ it is plausible to imagine that this process could not always be perfect, especially on the left side, where part of the left common cardinal vein naturally involutes. Even the left prevalence is not so high as in MS this fact is at least intriguing.

Left MD present a slight prevalence (57\%) but it is to highlight that the distribution of females is highly prevalent in left MD while in right MD genders are equally represented.

However, despite the side, MD has been correlated to a very wide range of very different disorders: herpetic neuropathy, ${ }^{25}$ autoimmune not cochlear pathologies, ${ }^{49,50}$ metabolic disorders, ${ }^{37}$ sleep disorders, ${ }^{51}$ water/salt imbalance ${ }^{52}$ cervical disorders ${ }^{53}$ allergies $^{54}$ and food intolerance with special regard to gluten sensitivity. ${ }^{55,56}$

Subject to the foregoing, it is our opinion that there is a gap between the so wide and so different disturbances connected to MD and a unique specific pathogenetic mechanism (EH). The stagnation per se due to jugular stenosis and/or intratemporal reflux or persistence of pathogens into the inner ear veins precisely due to venous stagnation does not seems to us enough.

Bearing in mind the venous cervico-cephalic drainage system into the context of the most complex waste brain clearance apparatus, constituted also by the glymphatic and the lymphatic systems, may bridge this gap.

\section{Ménière disease, chronic cerebrospinal venous insufficiency and glymphatic system}

The veins of the vestibule and semicircular canals accompany the arteries, and, receiving those of the cochlea at the base of the modiolus, join to form the internal auditory veins (or veins of labyrinth) which end in the posterior part of the superior petrosal sinus or in the transverse sinus. The common modiolar vein enters the bony channel immediately adjacent to the aqueduct to become the vein of the cochlear aqueduct, which in turn drains via the inferior petrous sinus into the IJVs. The cochlear aqueduct and the internal auditory canal communicate with the subarachnoid space $^{57}$ from where the CSF is driven into the Virchow-Robin spaces by a combination of arterial pulsatility, respiration, slow vasomotion and CSF pressure gradients. ${ }^{58}$ The forces that drives CSF towards brain parenchyma are the same that regulates venous cervico-cephalic drainage.$^{59}$ As it is known, the clearance system that utilizes perivascular tunnels formed by astroglial cells is the glymphatic system (GS).$^{19}$

Consequently, due to the anatomy of its structures, the inner ear is therefore connected both to the cervico-cephalic venous system and the GS. The GS also facilitates brain-wide distribution of glucose, amino acids, lipids and neuromodulators. ${ }^{60}$ In the same way, through the internal auditory canal, the same substance may reach the perilymphatic space. Acetazolamide, an inhibitor of carbonic anhydrases, is widely used in the treatment of $\mathrm{MD}^{61}$ to reduce $\mathrm{EH}$. However, acetazolamide is known to have a strong effect in reducing CSF formation. We think that the connection between inner ear and GS may explain the therapeutic effects of acetazolamide in MD: the reduction of CSF may induce a retrieval of perilymph reducing inner ear pressure.

The CSF movement into the parenchyma drives convective interstitial fluid fluxes within the tissue towards the perivenous spaces surrounding the large deep veins. The interstitial fluid is collected in the perivenous space from where it drains out of the brain towards the cervical lymphatic system.

GS functions mainly during sleep and it is largely disengaged during wakefulness. ${ }^{62}$ Nakayama and colleagues ${ }^{51}$ found in 35 definite MD that total sleeping time was significantly higher than in controls. Nevertheless, they also showed, for the first time, a poor quality of sleep with decreased deep sleep and an elevated arousal index. Yet, major sleep disorders like OSAS were rare and not MD specific: 4 cases in MD group and 3 in controls. Hence, it is unlikely that MD is due to reduced brain oxygenation or vascular disturbances as observed in OSAS, while, in our opinion, these data support the role of a GS disturbance in MD pathogenesis, at least in patients affected with a poor quality of sleep. In the same way the role of stress, that is considered as a trigger of MD attacks, ${ }^{63,64}$ may be interpreted: stress increase brain levels of norepinephrine that is known to be responsible for suppression of GS. ${ }^{65}$

The supposed GS disturbance may not to be, for example, the reactive gliosis of aging because there is an inverse correlation between age and $M D$ prevalence: ${ }^{66}$ MD typically starts between the ages of 20 and 50 . In addition, MD is not a neurodegenerative disease. Consequently, the expected GS disorders are 
unlikely to be linked to glia and astrocytes. It is more reasonable the involvement of the aquaporins (AQP): they regulate the production both of CSF and endolymph. $A Q P$ are membrane proteins also known as water channels that form pores in the membrane of biological cells. $\mathrm{AQP}$ selectively conduct water molecules in and out of the cell, while preventing the passage of ions and other solutes. Some of them, known as aquaglyceroporins, also transport across the membrane other small-uncharged solutes, such as urea, $\mathrm{CO}_{2}$, ammonia and glycerol, depending on the size of the pore. The so-called glycerol test (GT) is a still worldwide employed test for the diagnosis of MD. ${ }^{67}$ Ingestion of glycerol, 1.5 $\mathrm{g} / \mathrm{kg}$ body weight, causes a transient reduction of the hearing loss in the early stage of MD. In some cases improvements occur with considerable speech discrimination gain. No glycerol effect is seen in normal or cases of cochlear deafness of other types. The GT has been recently re-visited using the vestibular evoked potentials $^{68}$ instead of the Pure Tone Audiometry in order to have a more objective test. The action of glycerol is purely osmotic and the effect in MD is due to a reduction of intralabyrinthine pressure by means of specific AQP. It is interesting to note though, that AQP1 is expressed both in the choroid plexuses, that produce CSF, and in the stria vascularis of cochlea, that produce endolymph ${ }^{69}$ in the rats. In humans AQP1 is localized to fibrocytes and blood vessels of the underlying stroma and trabecular perilymphatic tissue: ${ }^{70}$ venous vessels are connected to the perilymphatic space, thus it is more probable that glycerol acts on endolynphatic pressure through the functional connections between venous system and GS than directly on inner ear.

In hypertension, another putative cause of MD $^{32}$ vasopressine dysregulation ${ }^{71}$ may be claimed and the anti-diuretic hormone results to be involved both in $\mathrm{GS}^{72}$ and in $\mathrm{EH}^{73}$

In conclusion, we can state that a defective venous system as in CCSVI interferes with regular function of GS. When another factor of GS dysfunction occurs, like stress or hypertension or sleep/awakness cycle dysregulation, inner ear may become unable to clear waste products of its metabolism either through the subarachnoid space and GS and the river-lake-pond system blocks leading to the endolymphatic hydrops.

\section{Ménière disease, chronic cerebrospinal venous insufficiency and lymphatic system}

A true lymphatic vascular system (LS) draining brain interstitial fluids and macromolecules has been very recently described. ${ }^{21,74}$
Generally speaking, LS is constituted by a network of lymphatic vessels in the dura mater of the CNS that drains out of the skull via the foramina of the base of the skull itself alongside arteries (the major branches of the middle and anterior meningeal arteries and the pterygopalatine artery), cranial nerves (I, V, IX, $\mathrm{X}$ and $\mathrm{XI}$ ) and veins. Lymphatic vessels have been observed in the dural lining of the cribriform plate, where some vessels passe through the skull into the nasal mucosa.

Dura mater lymphatic vessels drains brain ISF into deep cervical lymp nodes and experiments conducted in mice ${ }^{60}$ showed that impairment of LS compromises CNS macromolecule clearance. As stated also by Zamboni ${ }^{75}$ the interconnection of brain lymphatics with both the nasal mucosa and the deep cervical lymph-nodes allows T-cells and viruses to easily circulate into the brain and therefore in the inner ear too.

In MD either virus infections by Herpes viruse $^{76}$ or autoimmune viral activation ${ }^{77}$ or autoimmune diseases as thyroiditis ${ }^{78}$ have been considered as probable causes of the disease. The lymphatic vessels run down toward the base of the skull along the transverse sinus, the sigmoid sinus, the retrosigmoid vein and the rostral rhinal vein. The ES, the pond into Paparella's model, is placed on the posterior surface of the petrous portion of the temporal bone, where is in contact with the dura mater. The endolymphatic duct and ES perform absorptive and secretory, as well as phagocytic and immunodefensive functions: the ES is capable of antigen recognition and processing for initiation of an immune response. ${ }^{79,80}$

Reflux of venous blood flow into the petrous veins, and, as a consequence along modiolar veins, may alter the capability of the endolymphatic sac to drain via the lymphatic dura vessels with an alteration of its immunocompetence of the ES inducing recurrent flogistic EH episodes. $^{81}$

Another group of diseases claimed as MD cause are allergies, in general, food allergies, in particular. For almost a century inhalant and food allergies have been linked with MD symptoms. ${ }^{82}$ The prevalence of allergy in patients with MD is almost three times than in the general population. ${ }^{83}$ Wheat is one of the most common food allergens found in patients with MD, $68.2 \%$ according to Derebery and colleagues. ${ }^{84}$ In 2010 Derebery and colleagues ${ }^{85}$ defined the relation between allergy and MD. In 2012 Di Berardino and Cesarani ${ }^{55}$ confirmed the relation between immune response to the acid proteins fraction of gliadin in MD and in 2013 Di Berardino and colleagues ${ }^{56}$ reported recovery of MD after gluten-free diet.

Recently, Di Berardino and colleagues ${ }^{86}$ in a group of 116 definite MD patients (52 male $49.5 \pm 12$ years - 63 Female $49.8 \pm 13$ years) showed an incidence of $96 \%$ of atopic subjects by means of an allergo-immunologic battery including skin tests (prick test, prick by prick and/or intradermo reaction) intestinal permeability test and nasal mucociliary clearance (NMC) ${ }^{87}$ In MD NMC was significantly slowed.

It is well known the correlation between MD and nose disorders, generally read as to be sustained by Eustachian tube disturbances. ${ }^{88}$ In our opinion, the correlation between nose and EH pass through the LS: slowing of NMC in atopic patients may lead to slowing of allergens clearance in cervical lymphnodes and therefore a sensitization of the inner ear that become a hypersensitive target of the immune response to antigens. ${ }^{89,90}$

Venous disturbances may hamper inner ear lymphatic drainage through the perivenous lymphatic vessels. The putative correlation between cervico-cephalic venous regulation and nasal function may be sustained because the nose is not only a clearance organ but also a sophisticated conditioning system of the breathed air. It regulates both humidity and temperature of the inhaled air in order to maintain enough constant the physical characteristics of the air that reach the lungs despite the environmental conditions. This conditioning is due to the regulation of blood flow of the like-erectile tissue contained into each turbinate (three each side). As in corpus cavernosum, swelling of turbinate depends on arterial inflow and venous outflow. Congestion of the nose is also linked to body position, to be maximum on the side on which the subject is lying, head angle with respect to the trunk when supine, to be maximum when it is lower than $20^{\circ}$, and eventual pressure exerted on axillar vein with swelling of the same side. ${ }^{11}$ Lifting the head more than $20^{\circ}$ when sleeping on one hand facilitate nasal patency, on the other hand, it is usually suggested to a patient affected with CCSVI (so called inclined-bedtherapy). Furthermore, Eustachian Tube exercises using a small balloon to be inflate using the nose is usually suggested in MD patients in order to relieve aural fullness: this is nothing but repeated Valsalva maneuver that de facto facilitates venous drainage from the brain to the thorax.

In conclusion, we can state that a defective venous system as in CCSVI interferes with regular function of $L S$. When another factor of $L S$ dysfunction occurs, like virus infections or allergic reactions or autoimmune diseases, ES may become unable to clear throughout the lymphatic vessels, the river-lake-pond system blocks leading to the inflammatory $\mathrm{EH}$.

\section{Bridging the gap}

The presence of venous disturbances in a high percentage of patients affected with definite MD has been established. These abnor- 
malities seem to be disease specific due to the specific anatomic ${ }^{11}$ and functional ${ }^{7,8}$ findings observed. Furthermore, it seems that venous disturbances are also and organ specific interpreting Bavera and colleagues ${ }^{10}$ experience that, although the number of positive cases was very low, found $\mathrm{J} 3$ as the most represented dysfunctional level also in non-MD vestibular diseases. Obviously, this last observation needs to be confirmed in a largest number of patients.

This paper represents a putative model of interpreting the effects of CCSVI on inner ear under the light of brain GS and LF. From an epistemological point of view, a theory is a series of logical steps that are as valid as they are true while a model, the form of presentation we have chosen, is a series of logical steps as valid as useful. The helpfulness of our model is to allocate the various disorders and pathologies considered to be involved in MD in a logic and unitary explanation and, consequently, to facilitate therapeutic planning.

CCSVI may lead to endolymphatic hydrops through a pure hydraulic mechanism and therefore both an accurate case history and a complete evaluation of the patient are necessary in order to identify which compensatory circuits have been blocked to cause failure of compensation of the congenital abnormalities. On the basis of the Literature we think that the most probable blocked circuits in MD are the vertebral plexus, ${ }^{92}$ the thyroid veins ${ }^{78}$ and the anterior condylar confluent. ${ }^{93,94}$

Failure of compensation may regards also the GS and/or the LS. Again, an accurate case history and a complete evaluation of the patient are necessary in order to identify why GS and/or LS are not able to compensate the venous clearance.

On the basis of the literature we think that the most probable causes of a blocked GS in MD are sleep disorders, stress, ${ }^{95}$ nicotine ${ }^{95}$ and excitants abuse ${ }^{96}$ water/salt balance dysregulation ${ }^{97}$ intestinal disorders. ${ }^{98}$

On the basis of the Literature we think that the most probable causes of a blocked LS in MD are virus infections, ${ }^{99}$ viral reactivations, ${ }^{100}$ activation of viral inner ear epitopes, ${ }^{101}$ systemic autoimmune diseases, ${ }^{102}$ middle ear diseases, ${ }^{103-105}$ allergies, ${ }^{106}$ nasal disturbances, ${ }^{107}$ food intolerances. ${ }^{108}$

In conclusion, MD therapy requires accurate identification and treatment of each structural, metabolic ear, nose, throat and general diseases of the specific patient according to a model that we can define as a glocal model of ménière disease. This glocal model suggest to subdivide MD in two main groups: i) structural MD, in which a structural JBA may directly act impairing inner ear metabolism; ii) combined $\mathrm{MD}$, in which two out of three brain drainage systems are impaired or compensatory venous pathways are impaired in CCSVI-positive MD patients.

Considering that PTA induces immediately a significant relief of symptoms in MS patients but requires at least three months ${ }^{109}$ to obtain hearing improvement and vertigo attacks reduction in MD patients, further researches on the correlation between CCSVI and MD had to taken in account the possible causative role of the vertebral veins per se on inner ear disorders.

\section{References}

1. James A, Thorp M. Ménière disease. BMJ Clin Evid 2007;2007.

2. Committee on Hearing and Equilibrium. Guidelines for the diagnosis and evaluation of therapy in Ménière's disease. American Academy of Otolaryngology-Head and Neck Foundation, Inc. Otolaryngol Head Neck Surg 1995;113:181-7.

3. Paparella MM. The cause (multifactorial inheritance) and pathogenesis (endolymphatic malabsorption) of Ménière's disease and its symptoms (mechanical and chemical). Acta Otolaryngol 1985;99:445-51.

4. Bavera PM, Agus GB, Alpini D, et al. Results from 823 consecutive Duplex exams for CCSVI in a Vascular Centre. Acta Phlebol 2012;13:141-6.

5. Alpini D, Bavera PM, Di Berardino F, et al. Bilateral sudden sensorineural hearing loss and chronic venous cerebrospinal insufficiency: a case report. Phlebology 2013;28:231-3.

6. Alpini D, Bavera PM, Hahn A, Mattei V. Chronic venous cerebrospinal insufficiency (CCSVI) in Ménière disease. Case or cause? Science Med 2013;4:9-12.

7. Di Berardino F, Alpini DC, Bavera PM, et al. Chronic cerebrospinal venous insufficiency in Ménière disease. Phlebology 2015;30:274-9.

8. Filipo R, Ciciarello F, Attanasio G, et al. Chronic cerebrospinal venous insufficiency in patients with Ménière's disease. Eur Arch Otorhinolaryngol 2015;272:77-82.

9. Bruno A, Califano L, Mastrangelo D, et al. Chronic cerebrospinal venous insufficiency in Ménière disease: diagnosis and treatment. Veins and Lymphatics 2014; 3:77-80.

10. Bavera PM, Cecconi P, Alpini D, Di Berardino F. Venous abnormalities in Ménière disease. Veins Lymphat 2015;4:7.

11. Vannini ME, Menegatti E, Tessari M, et al. High resolution M-mode characterization of jugular veins valves in healthy volunteers and in patients with neurological disorders. Proc. 6th Annual ISNVD Meeting, 2016 Apr 29, New York, NY, USA.

12. Tagaya M, Yamazaki M, Teranishi M, et al. Endolymphatic hydrops and bloodlabyrinth barrier in Ménière's disease. Acta Otolaryngol 2011;131:474-9.
13. Merchant SN, Adams JC, Nadol JB Jr. Patophysiology of Ménière syndrome: are symptoms caused by endolymphatic hydrops? Otol Neurotol 2005;26:74-81.

14. Kim SU, Marcus DC. Regulation of sodium transport in the inner ear. Hear Res 2011;280:21-9.

15. Redfern RE, Brown M, Benson AG. High jugular bulb in a cohort of patients with definite Ménière's disease. J Laryngol Otol 2014;128:759-64.

16. Gianoli GJ, Larouere MJ, Kartush JM. Sacvein decompression for intractable Ménière's disease: two-year treatment results. Otolarygol Head Neck Surg 1998; 118:22-9.

17. Müller LO, Toro EF. Enhanced global mathematical model for studying cerebral venous blood flow. J Biomech 2014;17: 3361-72.

18. Toro EF, Zhang Q, Contarino C. Progress towards a global circulation mathematical model, incorporating detailed CSF and lymphatics dynamics. Proc. 6th ISNVD Annual Meeting, 2016 April 30, New York, NY, USA.

19. Jessen NA, Finmann Munk AS, Lundgaard I, Nedeergaard M. The glymphatic sistem: a beginner's guide. Neurochem Res 2015;40:2583-99.

20. Contarino C, Toro EF. A first step towards a mathematical model for the human lymphatic system. Proc. 6th ISNVD Annual Meeting, 2016 April 30, New York, NY, USA.

21. Louveau A, Smirnov I, Keyes TJ, et al. Structural and functional features of central nervous system lymphatic vessels. Nature. 2015;523:337-41.

22. Ciuman RR. Communication routes between intracranial spaces and inner ear: function, pathophysiologic importance and relations with inner ear diseases. Am J Otolaryngol 2009;30:193-202.

23. Vrabec JT. Herpes simplex virus and Ménière's disease. Laryngoscope 2003; 113:1431-8.

24. Gartner M, Bossart W, Linder T. Herpes virus and Ménière's disease. ORL J Otorhinolaryngol Relat Spec 2008;70:28-31.

25. Gacek RR. Ménière's disease is a viral neuropathy. ORL J Otorhinolaryngol Relat Spec 2009;71:78-86.

26. Raponi G, Alpini D, Volontè S, et al. The role of free radicals and plasmatic antioxidant in Ménière's syndrome. Int Tinnitus $\mathrm{J}$ 2003;9:104-8.

27. Di Berardino F, Cesarani A, Hahn A, Alpini D. Viral infection and serum antibodies to heat shock protein 70 in the acute phase of Ménière's disease. Int Tinnitus J 2007; 13:90-3.

28. Rassekh CH, Harker LA. The prevalence of migraine in Ménière's disease. Laryngoscope 1992;102:135-8. 
29. Ibekwe TS, Fasunla JA, Ibekwe PU, et al. Migraine and Ménière's disease: two different phenomena with frequently observed concomitant occurrences. J Natl Med Assoc 2008;100:334-8.

30. Koerte IK, Schankin CJ, Immler S, et al. Altered cerebrovenous drainage in patients with migraine as assessed by phase-contrast magnetic resonance imaging. Invest Radiol 2011;46:434-40.

31. Sammartano AM, Cassandro C, Giordano $\mathrm{P}$, et al. Medical therapy in Ménière's disease. Audiol Med 2012;10:171-7.

32. Warninghoff JC, Bayer 0, Ferrari U, Straube A. Co-morbidities of vertiginous diseases. BMC Neurol 2009;9:29.

33. Coelho DH, Lalwani AK. Medical management of Ménière's disease. Laryngoscope 2008;118:1099-108.

34. Nakayama M, Masuda A, Ando KB, et al. A pilot study on the efficacy of continuous positive airway pressure on the manifestations of Ménière's disease in patients with concomitant obstructive sleep apnea syndrome. JCSM 2015;11:1101-7.

35. Foster CA, Breeze RE. The Ménière attack: an ischemia/reperfusion disorder of inner ear sensory tissues. Med Hypotheses 2013;81:1108-15.

36. Weille FL. Hypoglycemia in Ménière's disease. Arch Otolaryngol 1968;87:555-7.

37. D'Avila C, Lavinsky L. Glucose and insulin profiles and their correlations in Ménière's disease. Int Tinnitus J 2005;11: 170-6.

38. Brookler KH. Ménière's syndrome, otosclerosis, and insulin resistance syndrome. Ear Nose Throat J 2006;85:82-3.

39. Lavinsky J, Wolff ML, Trasel AR, et al. Effect of hyperinsulinism on sensorineural hearing impairment in Ménière's disease: a cohort study. Otol Neurotol 2014; 35:155-61.

40. Pirodda A, Modugno GC, Mannari L, et al. Ménière's disease and the use of proton pump inhibitors. Swiss Med Wkly 2010;140:w13104.

41. Sajjadi H, Paparella MM. Ménière's disease. Lancet 2008;372:406-14.

42. Gadda G, Taibi A, Sisini F, et al. A simulation model to study the role of the extracranial venous drainage pathways in intracranial hemodynamics. Conf Proc IEEE Eng Med Biol Soc 2015;2015:7800-3.

43. Franz B, Altidis P, Altidis B, Collis-Brown G. The cervicogenic otoocular syndrome: a suspected forerunner of Ménière's disease. Int Tinnitus J 1999;5:125-30.

44. Simka M, Latacz P, Ludyga T, et al. Prevalence of extracranial venous abnormalities: results from a sample of 586 multiple sclerosis patients. Funct Neurol 2011;26:197-203.

45. Bavera PM. May symptoms of chronic cerebrospinal venous insufficiency be improved by venous angioplasty? An independent 4-year follow up on 366 cases. Veins Lymphat 2015;4:62-6.

46. Heermann J. Predominance of left ear in Ménière's disease, sudden deafness, inner ear damage, tinnitus and abnormally patent eustachian tube. Ear Nose Throat J 1993;72:205-8.

47. Reiss M, Reiss G. Laterality of sudden sensorineural hearing loss. Ear Nose Throt J 2014;93:318-20.

48. Lee BB, Laredo J, Neville R. Embryological background of truncular venous malformation in the extracranial venous pathways as the cause of chronic cerebrospinal venous insufficiency. Int Angiol 2010;29: 95-108.

49. Gazquez I, Soto-Varela A, Aran I, et al. High prevalence of systemic autoimmune diseases in patients with Ménière's disease. PLoS One 2011;6:e26759.

50. Greco A, Gallo A, Fusconi M, et al. Ménière's disease might be an autoimmune condition? Autoimmun Rev 2012; 11:731-8.

51. Nakayama M, Suzuki M, Inagaki A, et al. Impaired quality of sleep in Ménière's disease patients. J Clin Sleep Med 2010;6: 445-9.

52. Perlman HB, Goldinger JM, Cales JO. Electrolyte studies in Ménière's disease. Laryngoscope 1953;63:640-51.

53. Bjorne A, Berven A, Agerberg G. Cervical signs and symptoms in patients with Ménière's disease: a controlled study. Cranio 1998;16:194-202.

54. Di Berardino F, Barozzi S, Cesarani A. Allergy and Ménière disease. Eur Ann Aller Clin Immunol 2005;37:299-300.

55. Di Berardino F, Cesarani A. Gluten sensitivity in Ménière's disease. Laryngoscope 2012;122:700-2.

56. Di Berardino F, Filipponi E, Alpini D, et al. Ménière disease and gluten sensitivity: recovery after a gluten-free diet. Am J Otolaryngol 2013;34:355-6.

57. Schuknecht HF, Pathology of the ear. Philadelphia, Pa: Lea \& Febiger; 1993.

58. Ruız DSM, Gailloud P, Rufenacht DA, et al. The craniocervical venous system in relation to cerebral venous drainage. AJNR Am J Neuroradiol 2002;23:1500-8.

59. Sisini F, Toro E, Gambaccini M, Zamboni P. The oscillating component of the internal jugular vein flow: the overlooked element of the cerebral circulation. Behav Neurol 2015;2015:170756.

60. Yang L, Kress BT, Weber HJ, et al. Evaluating glymphatic pathway function utilizing clinically relevant intrathecal infusion of CSF tracer. J Trans Med 2013; 11:107.

61. Brookes GB, Hodge RA, Booth JB, Morrison AW. The immediate effects of acetazolamide in Ménière's disease. J Laryngol Otol 1982;96:57-72.

62. Xie L, Kang H, Xu Q, et al. Sleep drives metabolite clearance from the adult brain. Science 2013;342:373-7.

63. Söderman ACH, Möller J, Bagge Sjöbäck D, et al. Stress as a trigger of attacks in Ménière's disease. A case crossover study. Laryngoscope 2004;114:1843-8.

64. Juhn SK, Li W, Kim JY, et al. Effect of stress-related hormones on inner ear fluid homeostasis and function. Otol Neurotol 1999;20:800-6.

65. Berridge CW, Waterhouse BD. The locuscoreleus-noradrnergic system: modulation of behavioural state and state-dependent cognitive processes. Brain Res Rev 2003; 42:33-7.

66. Tyrrell JS, Whinney DJ, Ukoumunne OC, et al. Prevalence, associated factors, and comorbid conditions for Ménière's disease. Ear Hearing 2014;35:e162-9.

67. Klockhoff I, Lindblom U. Glycerol test in Ménière's disease. Acta Otolaryngol 1966:224:449.

68. Murofushi T, Matsuzaki M, Takegoshi H. Glycerol affects vestibular evoked myogenic potentials in Ménière's disease. Auris Nasus Larynx 2001;28:205-8.

69. Sawada S, Takeda T, Kitano H, et al. Aquaporin-1 (AQP1) is expressed in the stria vascularis of rat cochlea. Hearing Res 2003;181:15-9.

70. Lopez IA, Ishiyama G, Lee M, et al. Immunohistochemical localization of aquaporins in the human inner ear. Cell Tissue Res 2007;328:453-60.

71. Hoffman WE, Phillips MI, Schmid PG, et al. Antidiuretic hormone release and the pressor response to central angiotensin II and cholinergic stimulation. Neuropharmacol 1977;16:463-72.

72. Thrane AS, Thrane VR, Nedergaard M. Drowning stars: reassessing the role of astrocytes in brain edema. Trends Neurosci 2014;37:620-8.

73. Kumagami H, Loewenheim H, Beitz E, et al. The effect of anti-diuretic hormone on the endolymphatic sac of the inner ear. Pflügers Arch 1998;436:970-5.

74. Aspelund A, Antila S, Proulx ST, et al. A dural lymphatic vascular system that drains brain interstitial fluid and macromolecules. J Exp Med 2015;212:991-9.

75. Zamboni P. The discovery of the brain lymphatic system. Veins Lymphat 2015;4:58.

76. Welling DB, Daniels RL, Brainard J, et al. Detection of viral DNA in endolymphatic sac tissue from Ménière's disease patients. Otol Neurotol 1994;15:639-43.

77. Arnold W, Niedermeyer HP. Herpes simplex virus antibodies in the perilymph of patients with Ménière disease. Arch Otolaryngol Head Neck Surg 1997;123:53-6. 
78. Fattori B, Nacci A, Dardano A, et al. Possible association between thyroid autoimmunity and Ménière's disease. Clin Exp Immunol 2008;152:28-32.

79. Møller MN, Kirkeby S, Vikeså J, et al. Gene expression demonstrates an immunological capacity of the human endolymphatic sac. Laryngoscope 2015;125:E269-75.

80. Harris JP. Immunology of the inner ear: response of the inner ear to antigen challenge. Otolaryngol Head Neck Surg 1983;91: 18-23.

81. Harris JP, Fukuda S, Keithley EM. Spiral modiolar vein: its importance in inner ear inflammation. Acta Otolaryngol 1990;110: 357-65.

82. Duke WW. Specific tests in the diagnosis of allergy. Arch Int Med 1923;32:298-304.

83. Derebery MJ, Berliner KI. Prevalence of allergy in Ménière's disease. Otolaryngol Head Neck Surg 2000;123:69-75.

84. Derebery MJ. Allergic management of Ménière's disease: an outcome study. Otolaryngol Head Neck Surg 2000;122: 174-82.

85. Derebery MJ, Berliner KI. Allergy and its relation to Ménière's disease. Otolaryngol Clin North Am 2010;43:1047-58.

86. Di Berardino F, Soi D, Alpini D, et al. Gluten sensitivity and Ménière disease. Proc. 7th Symposium on Ménière Disease and Inner Ear Disorders, 2015 Oct, Rome, Italy.

87. Sleigh MA, Blake JR, Liron N. The propulsion of mucus by cilia. Am Rev Respir Dis 1988;137:726-41.

88. Hall CM, Brackman DE. Eustachian tube blockage and Ménière's disease. Arch Otolaryngol 1977;103:355-7.

89. Endicott JN, Stucker FJ. Allergy in Ménière's disease related fluctuating hearing loss preliminary findings in a dou- ble blind crossover clinical study. Laryngoscope 1977;87:1650-7.

90. Hsu L, Zhu XN, Zhao YS. Immunoglobulin $\mathrm{E}$ and circulating immune complexes in endolymphatic hydrops. Ann Otol Rhinol Laryngol 1990;99:535-8.

91. Ko JH, Kuo TB, Lee GS. Effect of postural change on nasal airway and autonomic nervous system established by rhinomanometry and heart rate variability analysis. Am J Rhinol 2008;22:159-65.

92. Bjorne A, Berven A, Agerberg G. Cervical signs and symptoms in patients with Ménière's disease: a controlled study. Cranio 1998;16:194-202.

93. Bjorne A, Agerberg G. Craniomandibular disorders in patients with Ménière's disease: a controlled study. J Orofac Pain 1995;10:28-37.

94. Bjorne A, Agerberg G. Symptom relief after treatment of temporomandibular and cervical spine disorders in patients with Ménière's disease: a three-year follow-up. Cranio 2003;21:50-60.

95. Siirala U, Gelhar K. Further studies on the relationship between Ménière, psychosomatic constitution and stress. Acta Otolaryngol 1970;70:142-7.

96. Ledesma ALL, Barreto MADSC, Bahmad F Jr. Caffeine effect in vestibular system. Int Tinnitus J 2014;19:77-81.

97. Golding-Wood PH. Water and salt balance in Ménière's disease. J Laryngol Otol 1960;74:480-8.

98. Collins SM, Surette M, Bercik P. The interplay between the intestinal microbiota and the brain. Nature Rev Microbiol 2012; 10:735-42.

99. Arnold W, Niedermeyer HP. Herpes simplex virus antibodies in the perilymph of patients with Ménière disease. Arch Otolaryngol Head Neck Surg 1997;123:53-6.
100.Gacek RA. A perspective on recurrent vertigo. ORL J Otorhinolaryngol Relat Spec 2013;75:91-8.

101.Platt M, Dillwall S, Elackattu A, et al. Mining immune epitopes in the inner ear. Otolaryngol Head Neck Surg 2014; 150:160-9.

102.Gazquez I, Soto-Varela A, Aran I, et al. High prevalence of systemic autoimmune diseases in patients with Ménière's disease. PLoS One 2011;6:e26759.

103.Harner SG, Blakey BW, Blakey JE. Smoking and middle ear disease: are they related? A review article. Otolaryngol Head Neck Surg 1995;112:441-6.

104.Nadol JB. Positive Hennebert's sign in Ménière's disease. Arch Otolaryngol 1977;103:524-30.

105.Sadé J, Ar A. Middle ear and auditory tube: middle ear clearance, gas exchange, and pressure regulation. Otolaryngol Head Neck Surg 1997;116:499-524.

106.Endicott JN, Stucker FJ. Allergy in Ménière's disease related fluctuating hearing loss preliminary findings in a double blind crossover clinical study. Laryngoscope 1977;87:1650-7.

107.Eccles R, Eccles KS. Asymmetry in the autonomic nervous system with reference to the nasal cycle, migraine, anisocoria and Ménière's syndrome. Rhinology 1981; 19:121-5.

108.Shambaugh GE Jr, Wie RJ. The diagnosis and evaluation of allergic disorders with food intolerance in Ménière's disease. Otolaryngol Clin North Am 1980;13:671-9.

109.Bruno A. CCSVI prevalence in Ménière disease and preliminary results of balloon venous angioplasty. Proc. 6th ISNVD Annual Meeting, 2016 Apr 30, New York, NY, USA. 